\title{
Coronavirus Disease (COVID-19) Outbreak- Recommendations for Health and Well-Being during Self-Quarantine at Home
}

\author{
Aparna Nagendra ${ }^{*}$ and Sowmya Rao $^{2}$ \\ ${ }^{1}$ Department of Nutrition and Dietetics, Bhagawan Mahaveer Jain Hospital, Girinagar, \\ Bengaluru, India \\ ${ }^{2}$ Department of Food and Nutrition Science, School of Life Sciences, Manipal Academy \\ of Higher Education- Dubai Campus, UAE \\ *Corresponding Author: Aparna Nagendra, Senior Dietitian, Department of Nutri- \\ tion and Dietetics, Bhagawan Mahaveer Jain Hospital, Girinagar, Bengaluru, India.
}

\author{
Received: April 17, 2020 \\ Published: April 28, 2020 \\ (C) All rights are reserved by Aparna \\ Nagendra and Sowmya Rao.
}

\begin{abstract}
The outbreak of SARS-CoV-2 has made considerable changes in the lives of people. One of the effective precautionary measures opted by Governments across the world is self-quarantine to safeguard its people against the infection and its after effects. Control measures planned and implemented have faced its own challenges, yet have been effective in one or the other way in controlling the spread of the infection. A lot of guidelines have been made available nationally as well as internationally for people to follow and safeguard themselves. The present situation of self-quarantine at home has its own challenges although this is the only best precautionary option available to control the spread of infection. The routine of many people has changed due to work from home and has resulted in a lot of changes in the way daily chores are being performed along with the intake of food and changes in exercise pattern. The present article is an attempt to offer healthy recommendations for people during self-quarantine at home.

Keywords: Corona Virus; Self-Quarantine; Healthy Living; Food Intake; Nutrients; Immune System; Physical Activity; Sleep
\end{abstract}

\section{Introduction}

World Health Organization has declared COVID-19 as a pandemic on $11^{\text {th }}$ March, 2020 [1]. The COVID-19 outbreak is posing unprecedented challenges and threats to patients and healthcare systems worldwide. This condition primarily involves the respiratory tract, but it may deteriorate to multi-organ failure and be fatal [2]. This virus is known to spread primarily through droplets of saliva or discharge from the nose when an infected person coughs or sneezes [3]. Mainly COVID-19 can be transmitted by 2 ways: Direct close contact: Exposure to the infected person (within 1 meter). Indirect contact: Touching the infected surface, clothes of infected person where the virus survives for several hours and touching one's face, mouth, eyes, nose which can transmit the virus [4]. Hence, it's important to practice respiratory etiquette. Governments around the world have taken all possible measures to control the spread and one of the effective measures taken at present is "Lock Down to Knock Down Corona". Many effective measures have been taken by the Indian government to handle the crisis situation and a country wide lockdown was announced for three weeks starting midnight on $24^{\text {th }}$ March to control the spread of COVID-19 [5].
Lockdown has resulted in countless changes in the day to day life, from schools, colleges, movie halls, social gatherings, ware houses being shut down in different parts of the country, as well as in many parts of the world [6]. But it is essential to note that the lockdown has met the bigger cause of controlling the spread of infection which is the need of the hour.

The present condition of lock down seems to have altered the routine of majority of the people across the globe. The resultant change in working pattern and increased leisure time to some, might also have increased the use of gadgets. Recommendations for all expected changing pattern of lifestyle is important so that people remain healthy during self-quarantine at home. Creating awareness on the importance of balanced diet and physical activity to maintain health and well-being during self-quarantine at home is essential at this hour of crisis.

The current situation is posing all possible challenges to the human race and efforts to emerge successful out of this situation is promising when there is collective effort from all. The present article is an attempt to provide some recommendations for people to keep themselves safe during this crisis hour along with information 
on healthy nutritious foods to include to increase immune system and also recommendations for general health and well-being.

\section{Symptoms and prevention steps}

The most common manifestations of COVID-19 includes mild to moderate symptoms like fever, dry cough, dyspnea, myalgia, fatigue, hypo-lymphaemia and radiographic evidence of pneumonia. Complications and death may occur in severe cases [7]. Table 1 gives the preventive measures recommended by WHO. It emphasizes on self-protection through regular hand wash using soap and water or using an alcohol based sanitizers frequently to stop the rate of spread of the virus. Centre of Disease Control and Prevention (CDC) emphasizes "physical distancing" and limiting face-to face contact with others and also advices on practicing at least 6 feet (2 meters) from other people [8].

\begin{tabular}{|c|c|}
\hline Measures & Recommendations \\
\hline Hand hygiene & $\begin{array}{l}\text { Wash hands regularly with soap and water, or } \\
\text { clean them with alcohol-based hand rub. }\end{array}$ \\
\hline $\begin{array}{l}\text { Social } \\
\text { distancing }\end{array}$ & $\begin{array}{l}\text { - Practice physical distancing by avoiding } \\
\text { unnecessary travel and staying away from } \\
\text { large groups of people. } \\
\text { - Stay home if you feel unwell. } \\
\text { - If suspected with infection, control mea- } \\
\text { sures to be taken and public health officials } \\
\text { to be notified. }\end{array}$ \\
\hline $\begin{array}{l}\text { Respiratory } \\
\text { etiquettes }\end{array}$ & 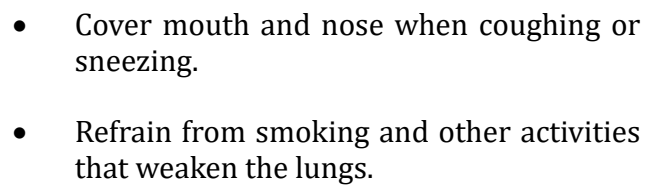 \\
\hline $\begin{array}{l}\text { Personal } \\
\text { habits }\end{array}$ & $\begin{array}{l}\text { - Do not share food with others from your } \\
\text { plate or vice-versa. } \\
\text { - Wash all vegetables and fruits before cook- } \\
\text { ing. } \\
\text { - } \quad \text { Rinse the cooking utensils, knifes and cut- } \\
\text { ting boards before using them. } \\
\text { - Cook meat or fish thoroughly. }\end{array}$ \\
\hline
\end{tabular}

Table 1: Preventive measures recommended by WHO.

Adapted from WHO standards, COVID-19 outbreak.

Steps taken by Indian government till date to monitor the spread of virus

The lock-down of the entire country was a major important decision taken by the Government to check the rate of spread in order to protect the Indian population. Physical and social distancing has been emphasized. Several measures have been taken by the Ministry of health and family welfare (MOHFW). Aarogya Setu App was launched to stay alert and informed about COVID-19 and its spread, various guidelines for the public have been given, effective use of social media connects like Facebook and what Sapp have been made, helpline numbers have been created state/district wise along with live helpdesk, awareness leaflets have been developed and information on preventive measures to be taken, preparation and usage of homemade masks and use of hand rub is being conveyed to the people [6].

\section{Work from home and food craving}

The outbreak of COVID-19 and different measures taken around the world to tackle it, has resulted in some observable changes that are hard to ignore. 'Work from home', popularly known as WFH, has sprung up into the mainstream and an increased proximity to kitchen and actions taking place in the kitchen might have an influence on the food craving of people working from home. Food craving can be defined as "an intense desire to consume a particular food that is difficult to resist" [9]. Hunger and appetite are two different sensations where hunger is often considered as an unpleasant sensation that compels a person to seek and eat food [10], while, appetite is defined as the process that leads to the qualitative selection and quantitative ingestion of specific foods [11]. In many people appetite can be a pleasant sensation that causes a person to desire and anticipate food. It is less easily localized than hunger and is often felt in mouth or palate. It depends more on odor or flavor and the pleasant memory of food [12]. Scientifically, it is a psychophysiological phenomenon of human nutrition which can be simply referred to as the urge to seek and consume specific food [13]. The food intake has to be self-monitored by individuals working from home. Binge eating should be monitored to avoid weight gain. It is essential to curb the temptation of eating in between meals when not hungry. Healthy snacks during snack time can be opted instead of processed and packaged food items. Table 2 gives some recommendations on healthy food items that can be opted for snacking.

\begin{tabular}{|l|c|}
\hline \multicolumn{1}{|c|}{ Food group } & Snacks \\
\hline Cereal based & $\begin{array}{c}\text { Seasoned puffed rice (Bhel /chat), seasoned } \\
\text { flattened rice (chewda), boiled corn, dhokla, } \\
\text { poha }\end{array}$ \\
\hline Pulse based & $\begin{array}{c}\text { Green gram salad (kosumbri), boiled whole } \\
\text { grams, sprouts, whole gram chat with vegeta- } \\
\text { bles, masala steamed dal dumplings. }\end{array}$ \\
\hline $\begin{array}{l}\text { Vegetables } \\
\text { and fruits }\end{array}$ & $\begin{array}{c}\text { Salad, boiled vegetables, green salad, steamed } \\
\text { vegetable momo's, Fruit salad, fresh fruit juices. }\end{array}$ \\
\hline Nuts & $\begin{array}{c}\text { Home-made ground nut chikki, roasted al- } \\
\text { monds, pistachio, boiled groundnuts, walnuts }\end{array}$ \\
\hline
\end{tabular}

Table 2: Some healthy snacking options.

Balanced diet and importance of strong immune system

A healthy balanced diet that provides all the essential macro and micronutrients like proteins, carbohydrates, fats, vitamins and minerals in balanced proportions is important for maintaining optimum nutritional status. These protective nutrients helps to build a robust immune system.

Immunity is the ability of the organism to resist the invasion of microorganisms and harmful substances [14]. The immune system plays a vital role in keeping the body healthy by providing a balance between the elimination of pervading pathogens and maintenance of tolerance to healthy tissue [15]. When the body resists the invasion of a particular species of microorganisms for the first time, it will have natural immunity, but the immunity acquired by the 
individual as a result of immunizations or vaccination of such microorganisms is known as acquired immunity. However, acquired immunity may be natural or artificial [14]. The gut and immune system also form an integrated complex structure that has evolved to provide effective digestion and defence system [16]. Ministry of AYUSH has provided recommendations to boost immune system. To mention a few, advice has been made to drink warm water throughout the day, to include spices like turmeric, cumin, coriander seeds or powder in cooking, and also has emphasised on the use of turmeric along with hot milk [17].

While the efforts of discovering a potent drug against the virus is underway, emphasis on creating awareness on balanced diet and healthy eating habits among people is essential. As no single food can meet all the nutrient needs of the body, emphasis on choosing a diet that includes foods from all the food groups is essential. Vitamin A is known to boost the immune system. It can be sourced from yellow and orange coloured vegetables and most of the green leafy vegetables like spinach, amaranth [18] etc. Seasonal vitamin $\mathrm{C}$ rich citrus fruits are also effective in boosting the immune system [19]. Probiotics like yoghurt and fermented food items are excellent sources to rejuvenate the composition of gut bacteria that aid in the nutrient absorption by the body [20]. Table 3 highlights some important micronutrients and its food sources. Thus, foods we choose and consume plays a major role in determining the overall health and immunity. Preference to home cooked food by including variety of ingredients as well as focus on traditional foods might be a wise choice now. Table 4 gives recommendations on selection of foods during self-quarantine at home.

\begin{tabular}{|c|c|}
\hline Nutrients & Sources \\
\hline Vitamin A & $\begin{array}{l}\text { Yellow and orange colored vegetables, green } \\
\text { leafy vegetables. }\end{array}$ \\
\hline $\begin{array}{l}\text { Vitamin B } \\
\text { (B6, B9, } \\
\text { B12) }\end{array}$ & $\begin{array}{l}\text { Cereals, legumes, green leafy vegetables, fruits, } \\
\text { nuts, dairy products, fish and egg. }\end{array}$ \\
\hline Vitamin C & $\begin{array}{l}\text { Orange, lemon, guava, kiwi, gooseberry, straw- } \\
\text { berries, melons, grapes, grapefruit, apricots, } \\
\text { broccoli, capsicum, spinach and mint. }\end{array}$ \\
\hline Vitamin D & $\begin{array}{l}\begin{array}{l}\text { Exposure to sunlight, milk and its products and } \\
\text { eggs. }\end{array} \\
\end{array}$ \\
\hline Vitamin E & Green leafy vegetables, vegetables oil \\
\hline Iron & $\begin{array}{l}\text { Dry fruits, legumes, pomegranate, fish and } \\
\text { chicken. }\end{array}$ \\
\hline Selenium & Cereals, nuts, mushrooms, chicken. \\
\hline Zinc & Wheat germ, dried beans, sea food, nuts, tofu \\
\hline
\end{tabular}

Table 3: Some important micronutrients and its food sources.

\section{Stress management}

Mental health plays an important role in the overall health of an individual. The need of the hour is to spread knowledge and awareness. It is important now not to spread any rumors and panic people. It is normal to feel sad, stressed, confused, scared or angry during a crisis [21], but it is essential to have a positive mind and handle the stress at this time. Following a routine through meditation, yoga, breathing exercises [17] will give a positive approach to life especially at this hour of crises when the increasing number of

\begin{tabular}{|l|}
\hline \multicolumn{1}{|c|}{ Recommendations } \\
\hline Choose home cooked food \\
- $\quad$ Eat freshly cooked home food which is generally regarded as
\end{tabular}

Eat freshly cooked home food which is generally regarded as safe and healthy

- Focus on traditional recipes and methods of cooking

- Enjoy simple meals rather than elaborate meals and maintain a meal timing

- Do not over eat just because a dish is one among the favourites

- Depending on the availability, include variety of foods from all the food groups

- Avoid Binge eating

- Avoid snacking when not hungry

- Given a choice, pick more fresh compared to packaged foods wherever and whenever possible depending on the availability of food items

- Follow all food safety and hygiene steps to stay safe and healthy

\section{Cereals, Pulses, Nuts and oilseeds}

- $\quad$ Cereals and cereal products made out of whole grains like Rice- varieties of red, brown, parboiled, Ragi, Jower, barley and other varieties grown, available and eaten locally

- Avoid refined products of cereal grains

- All varieties of dhals and whole grams available and grown locally, soaked, steamed, sprouted, boiled, sautéed and prepared into variety of dishes

- $\quad$ Nuts and oilseeds- ground nuts, cashews, almonds, sesame depending on affordability and availability

The storage and availability of non-perishable foods is easier compared to perishable items like fruits and vegetables. During times of non-availability choose options from non-perishable items which are also good sources of many important nutrients

\section{Milk and Meat products}

- $\quad$ Cow and buffalo milk is generally made available in packaged form or by individual distributors. In case of non-availability, alternatives can be used.

- Alternatives for milk in case on non-availability- milk powders as well as retort milk pouches. Toned and double toned packaged milk

- Monitor the use of processed cheese in the diet and limit the use depending on the health condition

- Depending on the availability of the animal foods locally, the choices can be made. For general health and well-being, usually white meats are recommended. Give preference to white meat like chicken and fish, which are low in fat compared to other red meats and ensure thorough cooking before consumption

\section{Fats and oils}

- $\quad$ Fats and oils are essential for providing energy and also aid in the absorption of fat soluble vitamins like A, D, E and K. Hence the use of fats and oils is essential in the diet

- However, excess use can pose problems and hence, it has to be monitored.

- $\quad$ Oils like Sunflower, ground nut, coconut oil, mustard oil available, grown, processed locally can be included

- Avoid hydrogenated fats in cooking

- Monitor the fried foods being included in the diet and limit the same 


\section{Water}

- Drink at least 8 - 10 cups of water filtered or potable water to stay hydrated

- Include healthy beverages made from freshly squeezed citrus fruits, other drinks like coffee, green tea and milk tea

- Avoid excess caffeine, sweetened fruit juices and fizzy drinks

Table 4: Recommendations for food choices during self-quarantine at home.

Note: All the above recommendations are made for healthy people and any health condition requiring a therapeutic diet for an individual has to be recommended by a practicing dietician and the same has to be monitored.

cases around the world is alarming and depressing. A restful quality sleep for adults is 7 - 9 hours. This will facilitate relaxation to the restless mind as well as improves body's immunity [22]. This is the time to start a hobby such as reading books, learning a new art that was missed all these years due to hectic schedules and use those skills to help manage emotions during the challenging time [21]. Spending quality time with family and strengthening the bonds might be achieved well now.

\section{Physical activity, sleep and use of gadgets}

At present, many healthy individuals are self-quarantined at home. Residing at home for a prolonged period of time can pose a significant challenge. It is a known fact that sedentary behavior with reduced physical activity can have negative effects on the health [3] and some studies stress on the relation of active life style with happiness [23]. A strong evidence shows that exerciser's are healthier than non-exerciser's, but most adults do not perform enough physical activity to achieve health and well-being [24]. So continuous exercise along with a healthy diet has been known to increase general health [23]. WHO recommends 150 minutes of moderate-intensity or 75 minutes of vigorous-intense physical activity per-week [25] or at least 30 minutes of daily exercise. These recommendations can still be achieved at home, with no special equipment and with limited space. Thus, during self-quarantine at home, staying active and including some form of physical activity might help to maintain the health status of people. Practicing yoga, push-ups, skipping, following guided sessions of aerobics online or using recoded videos, brisk walking inside the house, being physically active throughout the day and avoiding long periods of resting are some of the ways in which people can stay physically fit at home during self-quarantine.

Another variable which is a basis of healthy life is the sleep pattern. Sleep disorders have several social, psychological, economical outcomes and also affect healthy normal living [26] of an individual. A restful quality sleep of 7 - 9 hours for adults is suggested by American Academy of Sleep Medicine (AASM) and, Sleep Research Society (SRS) [22]. Adequate sleep is important during self-quarantine at home and either excess or lack of sleep might have an impact on the body.
Gadget addiction is a critical area of concern in the present era such as the use of smart phones, tablets, laptops and other electronics which is a threat to the social infrastructure in the future [27]. For instance, use of computer and other devices up to midnight, may affect the sleep pattern and it may disturb sleep. Addiction to use of mobile phone is related to depression symptoms [23]. Screen time of people during self-quarantine is important to be monitored. People working from home, as well as children taking online classes have to monitor their screen time. It is essential now for parents to engage their children in other activities after the online classes to develop child's creativity, like dancing, singing, reading books, learning a new language etc., which does not include looking at a screen.

Effective management of time will keep people active round the clock avoiding boredom due to staying at home. Spending only essential time on computer and laptops and limiting the use of phones during meal times and at least an hour or two before the bed time is essential. Conscious efforts to make healthy choices in diet, physical activity and use of gadgets is very important. Several studies in India and worldwide have shown that changes in dietary patterns, physical activity level and life style are related to increasing frequencies of obesity and the risk of diseases, such as coronary heart diseases and diabetes [28-33]. During self-quarantine at home, it may thus, be important to keep a watch on eating habits and activity pattern in order to maintain optimum nutritional status.

\section{Conclusion}

A Healthy lifestyle involves consuming balanced nutritious diet, staying physically active, maintaining good emotional and mental health along with a good sleep pattern. At this hour of crisis, when the normal routine of people around the world has changed, a sense of balance has to be achieved through different ways in order to remain healthy and fight against all the odds that the future has to offer. Self-quarantine can cause an additional stress and challenge the mental health of the people. Staying physically active, following relaxation techniques can be valuable tool to help remain calm and continue to protect health during this time. Self-monitoring, with respect to food choices, intake, physical activity, to keep oneself healthy is important not just now but even after the world comes out of this challenging time. The food that has been passed on since generations are definitely capable of providing sustenance to strengthen the immune system. Foods we eat can enhance our immune system but it is also essential to follow all the guidelines given by governing bodies to stay safe. A healthy balanced diet along with immune boosting nutrients, precautionary measures to prevent getting infected by the virus should be emphasized on. Along with keeping oneself safe, hope, prayer and support are the need of the hour. All the measure taken by the government is successful when people are aware of their responsibility and have a mind to think right and play their part to become an active volunteer to keep themselves and their family safe. 


\section{Bibliography}

1. Chatterjee K., et al. "Healthcare impact of COVID-19 epidemic in India: A stochastic mathematical model". Medical Journal Armed Forces India (2020).

2. Barazzoni R., et al. "ESPEN expert statements and practical guidance for nutritional management of individuals with SARS-CoV-2 infection". Clinical Nutrition (2020).

3. World health organization (WHO). "Coronavirus disease (COVID-19) outbreak".

4. Ministry of Health and Family Welfare Government of India, Prevention and management of Coronavirus.

5. Priyanka Pulla. "Covid-19: India imposes lockdown for 21 days and cases rise". British Medical Journal 368 (2020): 1251.

6. Ministry of Family Health and Welfare.

7. S Lei., et al. "Clinical characteristics and outcomes of patients undergoing surgeries during the incubation period of COVID-19 infection”. E Clinical Medicine (2020).

8. Coronavirus Disease (2019).

9. CK Martin. "Change in food cravings, food preferences, and appetite during a low-carbohydrate and low-fat diet". Obesity 19.10 (2011): 1963-1970.

10. Desai B. "Hormonal Regulation of Food Intake”. In: Handbook of Nutrition and Diet CRC Press. (2000): 425-436.

11. Blundell J., et al. "Appetite control: methodological aspects of the evaluation of foods". Obesity Reviews 11 (2010): 251-270.

12. Wadikar DD., et al. "Appetizer: A Food Category or Food Adjective?" Indian Journal of Nutrition 5.1 (2018): 185.

13. Blundell JE and Halford JCG. "Appetite: physiological and neurological aspects". In: Salder M (eds) Encyclopaedia of Human nutrition: academic press London 2 (1998): 121-126.

14. Haider Ibrahim Ali., et al. "The Effect of Nutrition on Immune System Review Paper". Food Science and Quality Management 90 (2019): 31-35.

15. Hsin-Jung Wu and Eric Wu. "The role of gut micro biota in immune homeostasis and autoimmunity". Gut Microbes 3.1 (2012): 4-14.

16. Cummings JH., et al. "PASSCLAIM--gut health and immunity". European Journal of Nutrition 43.2 (2004): 118-173.

17. Ministry of Ayush. "Ayurveda's immunity boosting measures for self - care during COVID 19 crisis" (2020).

18. Zhiyi Huang., et al. "Role of Vitamin A in the Immune System". Journal of Clinical Medicine Research 7 (2018): 258.
19. Anitra C Carr and Silvia Maggini. "Vitamin C and Immune Function". Nutrients 9.11 (2017): 1211.

20. Victoria Bell., et al. "One Health, Fermented Foods, and Gut Microbiota". Foods 7 (2018): 195.

21. World Health Organization, Coping with stress during the 2019-nCoV.

22. Jean-Philippe Chaput., et al. "Sleeping hours: what is the ideal number and how does age impact this?" Nature and Science of Sleep 10 (2018): 421-430.

23. DD Farhud: Impact of Lifestyle on Health". Iranian Journal of Public Health 44.11 (2015): 1442-1444.

24. Vicki S Conn., et al. "Meta-Analysis of Workplace Physical Activity Interventions". American Journal of Preventive Medicine 37.4 (2009): 330-339.

25. World Health Organization, Europe. “Coronavirus disease (COVID-19) outbreak". Stay physically active during self-quarantine.

26. Farhud DD and Tahavorgar A. "Melatonin hormone, metabolism and its clinical effects: a review". Iranian Journal of Endocrinology and Metabolism 15.2 (2013): 221-236.

27. Kumar AK., et al. "Assessment of gadgets addiction and its impact on health among undergraduates". The International Journal of Community Medicine and Public Health 5.8 (2018): 3624-3628.

28. Archer T. "Ageing, Obesity, Sedentary Lifestyle: Constituents for Poor Health and Performance". International Journal of $\mathrm{Nu}$ trition Sciences 1.3 (2016): 1011.

29. Chen JJ., et al. "Prevalence of Obesity and Chronic Disease Risks among Ethnic Groups of College Students in Southeast Texas". Austin Journal of Nutrition and Metabolism 1.1 (2014): 6.

30. Jääskeläinen., et al. "Stress-related eating, obesity and associated behavioural traits in adolescents: a prospective population-based cohort study". BMC Public Health 14 (2014): 321.

31. Ashok CK and Karunanidhi S. "Prevalence of overweight and obesity among young female college students in Chennai city". Journal of Obesity and Metabolic Research 3 (2016): 23-31.

32. Rao SG and Puttaraj S. "Determinants of Nutrition and Risk of Developing Non-Communicable Diseases in Adult Women". Indian Journal of Nutrition 2.2 (2015).

33. Chen JJ., et al. "Prevalence of Obesity and Chronic Disease Risks among Ethnic Groups of College Students in Southeast Texas". Austin Journal of Nutrition and Metabolism 1.1 (2014): 6. 


\section{Assets from publication with us}

- Prompt Acknowledgement after receiving the article

- Thorough Double blinded peer review

- Rapid Publication

- Issue of Publication Certificate

- High visibility of your Published work

Website: https://www.actascientific.com/

Submit Article: https://www.actascientific.com/submission.php

Email us: editor@actascientific.com

Contact us: +919182824667 